\title{
I-determinants for a successful PhD or postdoctoral outcome
}

This article was published in the following Dove Press journal:

Clinical Epidemiology

12 August 2016

Number of times this article has been viewed

\author{
Henrik Toft Sørensen ${ }^{1-3}$ \\ 'Department of Clinical Epidemiology, \\ Aarhus University Hospital, \\ Aarhus N, Denmark; ${ }^{2}$ Department \\ of Health Research and Policy, \\ ${ }^{3}$ Stanford's Center for Advanced \\ Study in Behavioral Sciences, Stanford \\ University, Stanford, CA, USA
}

\begin{abstract}
Many resources are invested in research training, but very little literature exists on predictors for a successful $\mathrm{PhD}$ and postdoctoral training outcome. A PhD program has two overall objectives: to extend knowledge about a hopefully important health topic and to provide extensive training to improve the $\mathrm{PhD}$ student's skills through learning research methods and collaboration. A substantial number of $\mathrm{PhD}$ students may run into some kind of problem in the course of their PhD program. In this article, some determinants all starting with an "I" and indicative of a good $\mathrm{PhD}$ outcome are reported. The successful $\mathrm{PhD}$ student can be described as having an Interest in the $\mathrm{PhD}$ program, an Incentive for the program, and an Idea of what he or she wants to investigate, showing Initiative, and having high personal Integrity and good Interpersonal relationships. When these so-called I-determinants are present, the likelihood of success in a $\mathrm{PhD}$ program is high. More evidence is available for selection of candidates for postdoctoral appointments since it is known that the postdoctoral candidate has completed a $\mathrm{PhD}$ program, published papers in peer-reviewed journals, and received awarded grants. However, other characteristics determine a successful transition of the postdoctoral candidate into a research leader. These determinants are Identity, Independence and Image, Implementation ability in terms of being able to implement decisions and projects, working with Innovative and Important topics, having In-depth knowledge of the research topic, being Interactive and Integrated with the scientific community, and Internationally oriented. In conclusion, regardless of the framework of research, the personal characteristics of a researcher play a very important role in the quality of research. Application of some of the principles mentioned in this article might allow decision to reach a more evidence-based way to recruit $\mathrm{PhD}$ students and postdoctorals. Keywords: academic training, epidemiologic determinants, outcome, $\mathrm{PhD}$, postdoctoral
\end{abstract}

\section{Introduction}

Research is vital to meet the challenges faced by the society. Clinical epidemiological research focuses on patient-oriented studies of risk factors, screening, diagnostics, treatment, and prognosis. Prevention and treatment of disease are the overarching goals of health research and thus the ultimate goal of our academic activity. ${ }^{1-3}$ It is important to keep this in mind, as academic success at an individual level is often measured solely in terms of publishing original peer-reviewed papers, defined by many as the "coin of the realm". ${ }^{4}$

The selection and training of future researchers are decisive factors in the quality of research. Currently, we face a shortage of talented researchers in clinical medicine to take up future challenges. ${ }^{4-8}$
Correspondence: Henrik Toft Sørensen Department of Clinical Epidemiology, Aarhus University Hospital, Olof Palmes Allé 43-45, 8200 Aarhus N, Denmark $\mathrm{Tel}+4587168215$

Email hts@clin.au.dk 
Large amounts of money are invested in research, and there are strict requirements for the research process with regard to preparing funding applications and operational protocols. However, the literature provides little information on the characteristics of successful students in $\mathrm{PhD}$ and postdoctoral programs. This information is needed to identify candidates who will bring the greatest value to the research enterprise at individual universities and hospitals and ultimately to patients.

A number of quantitative criteria are available to guide the selection of more senior researchers for open positions. These include number of papers published, position in author sequences, numbers of citations, and the H-index, although the relation between these criteria and the quality of research is debatable. ${ }^{9}$

As this type of information is not available for selecting $\mathrm{PhD}$ students and postdoctoral candidates, it is necessary to rely on grades from previous education, performance in earlier employment, strength of an application, and sometimes an interview. These characteristics are not always accurate indicators of success in graduate and postgraduate education. In medical school, for instance, excellent grades are often achieved through highly individualized study. Grades are not necessarily valuable in predicting which students will become successful in conducting research, as it requires a far wider range of competencies.

The training of clinical researchers is organized differently from one country to another, often based on tradition. In some European countries, many clinical researchers have a doctoral degree, while in the USA they may hold a master's degree. ${ }^{10}$ Similarly, postdoctoral work may be conducted solely as part of a research appointment or divided between research and clinical work in a clinical research appointment. ${ }^{8}$ The principles discussed in this perspectives paper apply to diverse courses of training.

More than 10 years ago, after having supervised a number of $\mathrm{PhD}$ students, I became interested in the factors characterizing those who completed their $\mathrm{PhD}$ programs in time, published papers in recognized peer-reviewed international journals, and experienced a clear improvement in their research skills during their training. Moreover, the $\mathrm{PhD}$ course should be a good personal experience for the students. In recent years, this interest has grown to include identifying which doctoral candidates on the threshold of a postdoctoral program would develop into independent researchers with innovative research agendas, with the aptitude for establishing their own team of researchers, and with the ability to finance their own research. ${ }^{8}$ An essential criterion for success as a senior researcher is the ability to obtain support for their own research from peer-reviewed funding agencies.
At the beginning of postdoctoral training, a clear picture starts to emerge of which postdoctorals formulate innovative research questions and which primarily conduct confirmative research. The challenge is to select individuals with talents and personal qualities that allow them to develop the skills of independent and resourceful researchers. Through acquisition of knowledge and honing of skills, they can then contribute to the solution of essential health problems. It is well documented that expert professional performance rests on knowledge and skills that cannot be acquired solely through teaching and individual study. The key requirement is personal commitment in addition to research experience. ${ }^{11,12}$

In this perspectives paper, I report some simple characteristics that I have identified as determinants of success in a $\mathrm{PhD}$ program and subsequent independent research in a postdoctoral program. My conclusions derive from personal experience - both retrospective mainly cross-sectional observations and more prospective cohort-oriented assessments.

I started by jotting down some notes and then began to work systematically on principles for selecting $\mathrm{PhD}$ students and postdoctorals. My analysis has not been conducted as a stringent epidemiological study. Rather, it may provide a qualitative description of a screening process and checklist. Based on my material (that is, the individuals we have identified as potential candidates), I have calculated some simple predictive values for individual variables. Serendipitously, many of the words I found to describe the successful researcher at the beginning of a career began with the letter "I".

\section{PhD program}

The recruitment of PhD students varies considerably from one institution to another and from one country to another. In some cases, it is an ad hoc procedure, in which potential $\mathrm{PhD}$ students contact desired supervisors. In other cases, notices are posted when grants are available. Such notices need to be worded as accurately as possible for successful recruitment. $\mathrm{PhD}$ programs have two overall objectives:

1. To extend knowledge about an important and as yet unclarified health topic via a research project. This project ranges from basic research, such as testing specific hypotheses related to mechanisms of disease, to more applied clinically oriented research, that is, studies of risk factors, diagnostic approaches, treatment and rehabilitation, and health services. ${ }^{13}$

2. To provide extensive training to improve the $\mathrm{PhD}$ student's competencies, through learning research methods and interaction with the research supervisor, other students, administrative and other staff, funding agencies, journal 
editors, teaching staff, and in some cases patients. ${ }^{14}$ Successful interaction requires initiative, resourcefulness, skills in communication and collaboration, and an approachable manner (both on the part of the student and the supervisor).

The student must process many inputs related to the research project and course program. This requires the goals and research plan for the project, as well as the teaching curriculum, to be well defined. In addition, to successfully complete a $\mathrm{PhD}$ research program, the student and the supervisor must possess a certain positive psychological energy as a driving force, which includes both motivation and enthusiasm.

The following elements - the content of the project and teaching, positive energy in the student and supervisor, and opportunities for wide-ranging interaction - all need to be present in the $\mathrm{PhD}$ training. In addition, independent and individual learning is an important element in a $\mathrm{PhD}$ program, which comes as a surprise to many $\mathrm{PhD}$ students. ${ }^{15}$

It is critical to the $\mathrm{PhD}$ outcome that the research project be sound. It must be realistic, preferably "novel", of clinical and public health relevance, ${ }^{16}$ and sufficient funding must be available covering both project costs and the student's compensation (Figure 1). A good early predictor of success in a $\mathrm{PhD}$ program is the student's assumption of responsibility for preparing funding applications and seeking administrative support and advice.

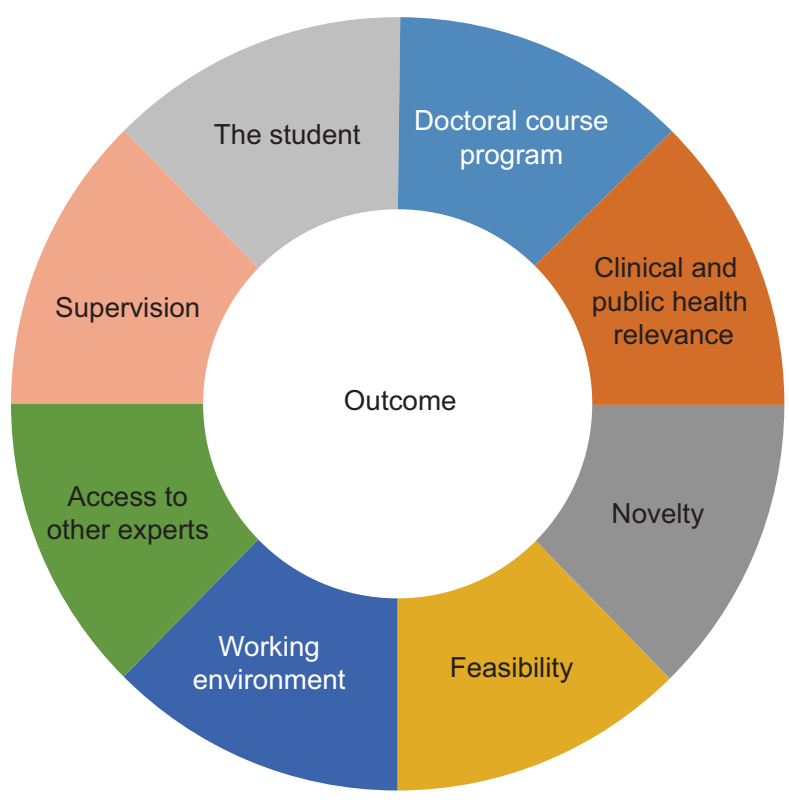

Figure I Factors associated with the scientific outcome of doctoral research.
A competent supervisor clearly specifies the division of responsibility between supervisor and student. Supervisors must be aware of their own knowledge and limitations. Many supervisors have difficulty finding sufficient time for supervision and for familiarizing themselves with the subject content of a specific research area and make demands. In my experience, problems in successfully completing a $\mathrm{PhD}$ program stem 1) from a poorly planned and inadequately planned project, 2) from clinical supervisors who are insufficiently aware of their own level of competency (eg, in their grasp of research methodology) and who do not have enough time for supervision, and 3) from supervisors with insufficient clinical knowledge or a lack of understanding of the framework for clinical research, despite their expertise in methodology.

It is not always clear at the beginning of a $\mathrm{PhD}$ program that a student lacks the qualifications necessary to undertake research on a given subject. Early signs that the process is not going smoothly are student ambivalence, lack of motivation, or when a student comes to the department infrequently or cancels meetings. Surprisingly, many $\mathrm{PhD}$ students find it difficult to accept advice and guidance. They may be sensitive to criticism or feel they are highly knowledgeable. Despite their intelligence, they will not function well in a research environment. A student's performance can also be impacted by personal challenges, such as family problems or a change in a spouse's employment.

Supervisors and chairs in a good research department should promote the following qualities:

- A good working environment, in which management clearly communicates the department's vision, mission, and values - particularly the soft values such as honesty, communication, support, respect, fairness, predictability, competence, and aspirations.

- Responsibility, demonstrated by behaving positively, holding to agreements, preparing carefully for meetings, arriving on time, observing deadlines, being result-oriented, respecting all groups of staff, collaboratively securing resources in the research environment, making an extra effort to use resources conscientiously, and maintaining high ethical standards.

- Collaboration, achieved by actively sharing knowledge and information, giving constructive and honest criticism, contributing to solutions and improvements, and especially allowing time for students to solve problems themselves. A supervisor must articulate professional questions and resolve dilemmas to ensure progress in the research. 
An atmosphere of institutional and individual competition is present in many research environments, produced by the great competition for research funding and appointments. Several different professional groups may be employed in a department, each with its own professional identity, and persons of different nationalities may converse in their own languages.

In our program, at least $20 \%-25 \%$ of $\mathrm{PhD}$ students run into some kind of problems in the course of their $\mathrm{PhD}$ program. Approximately $40 \%-45 \%$ deliver a quality $\mathrm{PhD}$ dissertation based on quality papers. Approximately $40 \%$ continue with some kind of research activities after their $\mathrm{PhD}$. Only $\sim 5 \%-10 \%$ of $\mathrm{PhD}$ students, however, ultimately become independent researchers with their own research teams. In many cases, the reasons for the problems are not just the $\mathrm{PhD}$ students' qualifications but also include poorly planned projects and poor supervisors. In a number of cases, the project runs short of funds.

These data correspond to data from the Wellcome Trust and Cancer Research, UK, that showed that among clinical $\mathrm{PhD}$ graduates, a third progressed to a formal academic post. The British Heart Association has reported that only 40\% of clinicians who completed a $\mathrm{PhD}$ continued to be active in research. ${ }^{5}$

If a student enters a $\mathrm{PhD}$ program from necessity or coercion (for instance, as a qualification for promotion or a career), the prognosis is far less favorable than when the driving force is a genuine interest in research. Early on, it is important to clearly identify the incentive for undertaking a $\mathrm{PhD}$ program.

Personally, I always set a 3-month probation period before a $\mathrm{PhD}$ student is accepted, to clarify whether it was the right choice, both for the PhD student and for the department. A firm agreement about a 3-month probation period does not result in a loss of face for a student who does not progress to final enrollment. It is important to make the possibility of failure clear. The probation period allows me to develop a clear idea of whether the "I-determinants", mentioned previously and discussed in detail subsequently, are present.

In selecting PhD students, it is important to be aware of the wide range of components subsumed under the concept of competencies: personal characteristics, talent, knowledge, skills, and behavior. While the individual basis (personal characteristics and talent) is not easily changed, it is possible for a supervisor to influence the last three elements. ${ }^{12}$ Positive personal characteristics and talent are, however, the factors that distinguish top researchers from average researchers. In addition, successful researchers are characterized by having clear goals and a research agenda. ${ }^{4,8}$ They also benefit from a committed mentor ${ }^{10,17,18}$ with deep insight about a subject, who is capable of giving qualified and independent advice without conflict of interest. Successful researchers are sociable and have good collaborative skills. They identify with their profession and understand the dynamics and funding climate of a research department.

\section{I-determinants for successful PhD students}

As mentioned previously, over the years I have recorded a number of characteristics that are indicative of a promising $\mathrm{PhD}$ student. By chance, my notes included words beginning with I to a surprising extent. I have adjusted my list to make it fit the I-determinants and to promote understanding and dissemination.

Although not exhaustive, the following terms describe the successful PhD student (Figure 2):

1. Interest in the PhD program: this interest must be the essential motivation for seeking to obtain a doctorate, preferably combined with a professional need to obtain the degree. This I-determinant is a key marker for progression in the program and acquisition of knowledge and skills. Prior research experience (for instance, as a medical student) with peer-reviewed publications is also an excellent predictor. ${ }^{19}$

2. Incentive: potential candidates fall between two extremes regarding incentive. Some candidates wish to obtain a doctorate for career reasons. If this is combined with

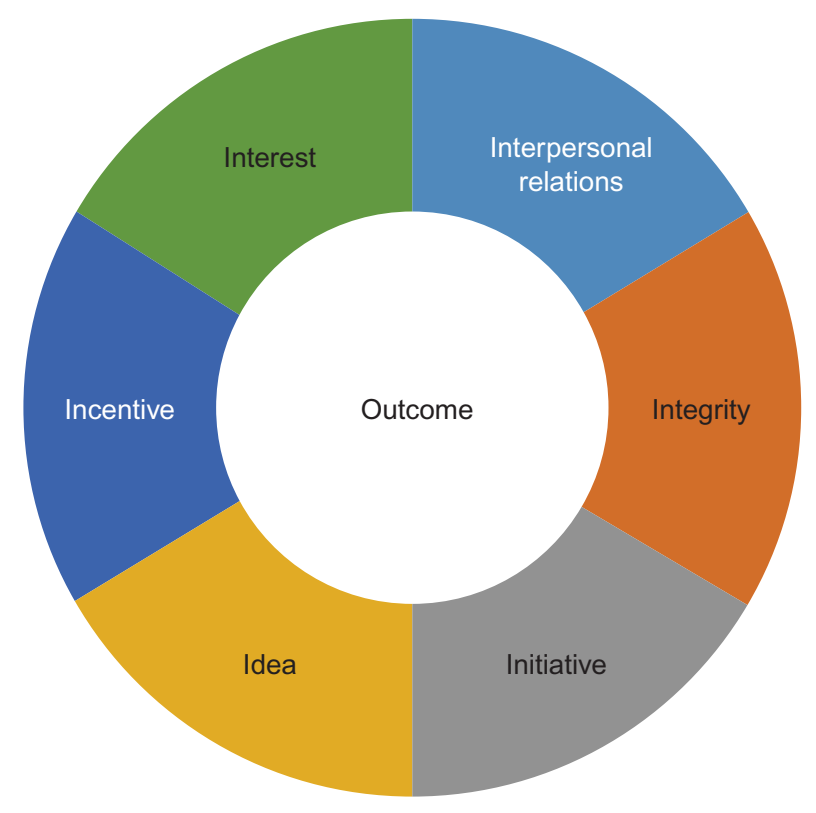

Figure 2 Determinants associated with the successful doctoral student. 
a genuine interest, it is a good predictor of success. At the same time, a career incentive without an interest in research is a negative predictor. This is also true if a candidate wishes to obtain a break from the clinical routine, to avoid other responsibilities, or to avoid a transfer to another city. Both the concepts "interest" and "incentive" are closely related to motives. In psychology, several types of motives have been distinguished. Internal or intrinsic (also called genuine) motives are related to the activities themselves. ${ }^{20}$ For example, a PhD student is motivated to create important insight and knowledge. This will often include hard work and struggle to reach the desired outcome that is intrinsically connected to the activity itself. In contrast to internal motives are the so-called instrumental motives, where the motive bears no intrinsic relation to the activity itself. Some instrumental motives could be that the $\mathrm{PhD}$ student wants to get promoted, get a specialist position, or a good salary. Psychological research suggests that instrumental motives may have negative impact on internal motives. Internal motivation predicts positive outcomes, while multiple motives may have negative impact in an educational context. ${ }^{20}$

3. Idea: if the candidate has a good idea of what he or she wants to investigate, has sought out, and read a selection of the literature on the question to be researched, and if the idea is realistic, the probability of success is good. If, in addition, the idea is focused, the prognosis is better than if the idea is broad and diffuse.

4. Initiative: if the student shows initiative, is always well prepared, drafts proposals, and meets deadlines, the probability of success is far more likely than for a reactive student who expects proposals to be provided by a supervisor who always has to take the initiative. Failure to meet deadlines is a very unfavorable predictor. The prognosis is, as expected, far better for proactive personalities than for reactive personalities.

5. Integrity: personality plays an essential part in interactions with others. Personal characteristics predictive of success in a $\mathrm{PhD}$ program are responsibility and realistic self-confidence. Arrogance and ambivalence have the opposite effect. The prognosis is good for students with their own clearly grounded approaches to research, the research project, and the supervisor. The prognosis is also good for students who take responsibility for themselves and their programs and understand that obstacles and challenges help to drive personal development in the research process. The role of supervision should be very clearly defined as a professional relationship rather than a tutorial friendship. ${ }^{15}$ This commentary does not cover supervision, which is an independent discipline. ${ }^{15,21}$ Clear communication is important in the relationship between supervisor and student. Expectations must match, and a framework must be agreed upon for the supervisory process. As stated earlier, it is important for a supervisor to have the right interest, competencies, and knowledge in relation to a given $\mathrm{PhD}$ project. At the same time, the student's personal integrity is a prerequisite for the necessary discipline and time management (a major problem for many). Some universities issue formal contracts between the institution and $\mathrm{PhD}$ students.

6. Interpersonal relationships: the ability to communicate well and share knowledge plays a major role in successful interaction with a supervisor, other PhD students, and employees in the department. During interviews, I try to uncover the ability to maintain and develop positive interpersonal relationships, relying on the following words as signals: motivation, willpower, sensitivity, expectations, psychological balance, loyalty, frequency and duration of previous positions, and earlier conflicts.

If all the I-determinants discussed previously are present, the likelihood of success in a PhD program is high.

In my daily work, I operationalize my evaluation of applicants to a PhD program by scoring them on each of the six "I-determinants" on a scale of $1-5$, where 1 is lowest and 5 is best. This means there is a maximum score of 30 points. Not surprisingly, a score $>20$ is a good determinant of success in a program, while a score $<18$ is a strong predictor of less good outcome (predictive value 0.69). If the score is $>23$, the predictive value is $\sim 90 \%-95 \%$ with the lowest value for incentive and highest for initiative. For a cut point of 23 points, the negative predictive values are between 0.26 and 0.53 . In a multiple logistic regression model, the estimates are imprecise but the strongest positive predictors are interpersonal relationships, interest, and incentive, while idea is a bit weaker predictor, but the discriminatory interpretation should be cautious.

\section{I-determinants for postdoctorals}

More evidence is available for selection of candidates for postdoctoral appointments. The candidate has completed a $\mathrm{PhD}$ program, and it is known whether he or she completed the program on schedule, published papers in peer-reviewed journals, was awarded grants, and whether the process went smoothly. These factors must naturally be considered in light of the candidate's framework for conducting research and the characteristics of his or her supervisor. An overlooked and 
underprioritized area in international research is development of postdoctorals as research leaders.

Of course, the I-determinants described previously for $\mathrm{PhD}$ students also play a very important role in postdoctoral research. However, it is a considerable leap from being a $\mathrm{PhD}$ student to being a postdoctoral. A well-developed capacity for critical thinking, conceptualization, and reflection is an important predictor for success in independent research. This must be combined with independent, innovative thinking and the ability and confidence to challenge existing hypotheses. At the postdoctoral stage, candidates must examine whether they can be research leaders, with the ability to supervise others and to integrate them into a research team. Understanding of leadership is essential and required, that is, as a process of inspiration, influence, setting a course, working with others, and thereby creating value. On this basis, I developed a series of I-determinants for postdoctorals (Figure 3), identified through interaction with $>100$ researchers at the postdoctoral level or higher with whom I have worked with over the years, nationally and internationally.

1. Identity, Independence, and Image (self-image): postdoctorals who are "big picture" thinkers and aware of their own reputation, and their value in the research community, in a realistic way, often develop into successful independent researchers. Those who are committed to self-management and interested in leadership in research institutions possess essential positive characteristics. As well, postdoctorals who are persistent, who can tolerate

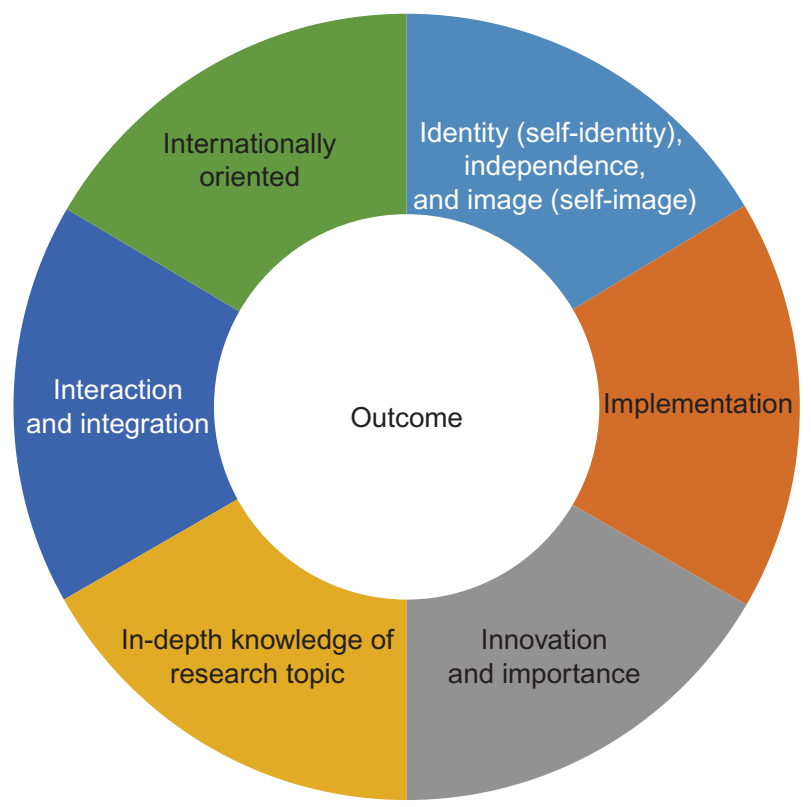

Figure 3 Determinants associated with a successful outcome in a postdoctoral program. refusals of papers and grants, and who can revise up to 20-30 drafts of a paper before it is submitted, also possess qualities required for success as research leaders. As well, the successful researcher is highly inquisitive and consciously sets time aside each day to learn something new. A certain degree of isolation, loneliness, and opposition is part of a postdoctoral program, which must be tolerated and handled by a successful postdoctoral.

2. Implementation: ability to implement decisions and projects and see them through to completion is important determinants of a successful postdoctoral. In many cases, a $\mathrm{PhD}$ program will have clarified whether these qualities are present. A good marker is whether the PhD program was completed on time. The ability to set priorities and manage time is essential determinants of the ability to complete one's research. Poor time management is a common problem, especially among $\mathrm{PhD}$ students and postdoctorals, although they spend many hours on their work.

3. Innovative and Important topics: if a postdoctoral published papers in leading peer-reviewed international journals as a $\mathrm{PhD}$ student and is able to formulate projects building on this experience, or in new areas, he or she is likely to have the skills characterizing a successful research leader.

4. In-depth knowledge of research topic: able and productive researchers are thoroughly familiar with their research field, including its textbooks and key publications., ${ }^{4,8}$ They have a clear, focused research agenda, possibly with multiple subagendas. ${ }^{8}$

5. Interactive and Integrated with the scientific community: successful postdoctorals are well mentored and supported by their own department and university. They present their results at scientific meetings and may participate in the work of professional associations. They know key people in their subject field. They have already gained experience in providing supervision.

6. Internationally oriented: periods spent in another international research environment during a $\mathrm{PhD}$ program are positive predictors of successful postdoctorals. A change in research environment, when the candidate has contributed personally to finding the necessary funding, is an experience that cannot be overvalued. Participation in collaborative international research is a key predictor of a postdoctoral's future success.

\section{Conclusion}

Research plays a central role in ultimate success in preventing and treating disease. Regardless of the framework for research, the personal characteristics of a researcher 
play a very important role in the quality of the research. Our knowledge is limited about ways of selecting $\mathrm{PhD}$ students and postdoctorals at the beginning of their research careers, who will produce the greatest value for society. The application of the principles discussed in this paper hopefully will allow decisions to be reached in a more evidence-based way.

\section{Acknowledgment}

HTS was supported by the Program for Clinical Research Infrastructure (PROCRIN) established by the Lundbeck Foundation and the Novo Nordisk Foundation and by the Aarhus University Research Foundation. The author is Editorin-Chief of Clinical Epidemiology.

\section{Disclosure}

The author reports no conflicts of interest in this work.

\section{References}

1. Rothman KJ. Epidemiology. An Introduction. 2nd ed. Oxford: Oxford University Press; 2012:235-253.

2. Weiss NS. Clinical Epidemiology. The Study of the Outcome of Illness. 3rd ed. Oxford: Oxford University Press; 2006.

3. Fletcher RH, Fletcher SW, Fletcher GS. Clinical Epidemiology. The Essentials. 5th ed. Philadelphia, PA: Lippincott Williams \& Wilkins; 2014

4. Applegate WB, Williams ME. Career development in academic medicine. Am J Med. 1990;88(3):263-267.

5. Ranieri V, Barratt H, Fulop N, Rees G. Clinical academics' postdoctoral career development. BMJ. 2015;351:h6945.
6. StewartPM.Academic medicine: a faltering engine. BMJ.2002;324(7335): 437-438.

7. Clark J, Tugwell P. Who cares about academic medicine? BMJ. 2004; 329(7469):751-752.

8. Rabeneck L. A career in GI epidemiology. In: Talley NJ, Locke GR 3rd, Saito YA, editors. GI Epidemiology. Oxford, UK: Blackwell Publishing Ltd; 2007:103-108.

9. Sørensen TIA. [Citomaniacs hærger]. Weekendavisen. 2016.

10. Lee TH, Goldman L. Models of postdoctoral clinical research training. J Investig Med. 1995;43(3):250-261.

11. Wakherhausen S. Professionsidentitet, sædvane og akademiske dyder. In: Hansen NB, Gleerup J, editors. Videnteori, professionsuddannelse og professionsforskning. Odense, Murkebjerg: Syddansk Universitetsforlag; 2004:19-27.

12. Kalman H. The Structure of Knowledge. Uppsala: Swedish Science Press; 1998.

13. Goldman L. Blueprint for a research career in general internal medicine. J Gen Intern Med. 1991;6(4):341-344.

14. Illeris K. Laring. 2nd ed. Roskilde: Roskilde Universitetsforlag; 2013.

15. Wisker G. The Good Supervisor: Supervising Postgraduate and Undergraduate Research for Doctoral Theses and Dissertations. London: Macmillan; 2005.

16. Hulley SB, Cumming SR, Browner WS, Grady DG, Newman TB. Designing Clinical Research. Philadelphia: Lippincott, Williams and Wilkins; 2007:3-15.

17. Lewis JD. The pathway to academic success starts during fellowship. Gastrointest Endosc. 2005;61(4):587-588.

18. Sackett DL. On the determinants of academic success as a clinicianscientist. Clin Invest Med. 2001;24(2):94-100.

19. Segal S, Lloyd T, Houts PS, Stillman PL, Jungas RL, Greer RB 3rd. The association between students' research involvement in medical school and their postgraduate medical activities. Acad Med. 1990;65(8):530-533.

20. Wrzesniewski A, Schwartz B, Cong X, Kane M, Omar A, Kolditz T Multiple types of motives don't multiply the motivation of West Point cadets. Proc Natl Acad Sci U SA. 2014;111(30):10990-10995.

21. Delamont S, Atkinson P, Parry O. Supervising the PhD: A Guide to Success. Oxford: Oxford University Press; 1997.
Clinical Epidemiology

\section{Publish your work in this journal}

Clinical Epidemiology is an international, peer-reviewed, open access, online journal focusing on disease and drug epidemiology, identification of risk factors and screening procedures to develop optimal preventative initiatives and programs. Specific topics include: diagnosis, prognosis, treatment, screening, prevention, risk factor modification,

\section{Dovepress}

systematic reviews, risk and safety of medical interventions, epidemiology and biostatistical methods, and evaluation of guidelines, translational medicine, health policies and economic evaluations. The manuscript management system is completely online and includes a very quick and fair peer-review system, which is all easy to use. 